\title{
The Effect of Nutrition on Immune System Review Paper
}

\author{
Haider Ibrahim Ali ${ }^{1}$ Sarmad Ghazi Al-Shawi ${ }^{1} \quad$ Hassan Nima Habib ${ }^{2}$ \\ 1.Food Science Department-Agriculture College-Basrah University- Iraq \\ 2.Animal Production Department-Agriculture College-Basrah University- Iraq
}

\begin{abstract}
Introduction
The most basic definition of immunity is the ability of the organism to resist the invasion of microorganisms and harmful substances. Blood plays an important role in immune development due to the presence of certain types of white blood cells in the blood and in some other tissues have the ability to eliminate strange organisms and destroy it as well the blood plasma contains antibodies made by certain immune cells to resist any strange proteins or any other substances linked to proteins, such proteins that stimulate the body tissues to form antibodies called antigen generators or antigens.Some objects work on precipitation these strange proteins to isolate them, so it called precipitins, while others work on the conglomerate of microorganisms or red blood cells. These are called agglutinins, while some act on neutralizing of toxins, called antitoxins.Immunizations are either natural immunity or innate immunity or acquired immunity. When the body resists the invasion of a particular species of microorganisms for the first time, it will have natural immunity, But the immunity acquired by the individual as a result of immunizations or vaccination of such microorganisms is known as acquired immunity, However, acquired immunity may be natural or artificial. The immunity generated in the individual an actual measles infection is known as naturally acquired immunity, but the immunity that is formed as a result of vaccinating the individual of typhoid or diphtheria vaccine is artificially acquired immunity $(1,2,3,4,5)$.However, acquired immunity may be natural or artificial. The immunity generated in the individual following an actual measles infection is known as naturally acquired immunity (6).
\end{abstract}

DOI: $10.7176 / \mathrm{FSQM} / 90-06$

Publication date:September $30^{\text {th }} 2019$

\section{Colostrum and strengthening the immunity of infants}

First, Colostrum is the breast secretion that follows the release of mature milk, which is different in form and nutritional properties, it is a yellow liquid water, but it forms a high degree of immunity to infants by affecting it on the digestive tract more than its absorption in the blood later. The colostrum is exposed from 5-10 days after birth for changes in the chemical composition and its natural properties until it reaches at the tenth day to its natural properties of mature milk $(7,8)$.

It is worth mentioning that the materials responsible for the anti-infection properties in the mother's milk are the colostrum particles which are stable in the acidic environment of the stomach and resistant to digestive enzymes (9), including lysozymes, which has a concentration of 300 times compare to what is found in cow's milk, which attacks and destroys the cell membranes of bacteria after inhibition it with peroxides found in breast milk, infant saliva and vitamin C found in colostrum (10), in addition, lactoperoxidase which kills Streptococcus bacteria (11).

Another group of cells that have a protective role which are macrophages, these molecules are not absorbed but they improve the immune system of infants by protecting them from pathogenic bacteria and viruses such as influenza, diphtheria, and poliomyelitis (12), these cells also create complements, which are a protein that enters a series of reactions that produce immunity against infectious organisms (13).

Lactoferrin is a protein containing iron that has immunological properties, it is found in colostrum and mature mother's milk, this substance inhibits the growth of $E$. coli and Staphylococcus bacteria by binding the iron that necessary for the growth of these bacteria, in case of addition of iron to the meal food, the lactoferrin becomes saturated and any additional iron in a free state supports the growth of infectious organisms, so children who take iron supplementation are then exposed to infection $(14,15)$.

On the other hand, there is a carbohydrate-containing nitrogen found in breast milk is the Lactobacillus bifidus factor and this substance creates an encouraging environment in the digestive tract activates the growth of Lactobacillus bifidus bacteria, and these bacteria produce acetic acid or lactic acid from lactose, which inhibits the growth of pathogenic microbes, which reduces the infant's susceptibility to infectious diseases and inhibits the growth of $E$. coli $(16,17)$.

Lactulose exists in large quantities in mother's milk, which is derived from lactose, it is found in larger quantities in heat-treated cow's milk comparing to non-heat-treated cow's milk. It is worth mentioning that Lactobacillus bifidus grows when eating a rich meal of high lactose and low protein, and the ratio of lactose/protein in breast milk is 1:7 compared to bovine milk 1:4. (18).

In addition, a group of proteins (Immunoglobulins) in breast milk play an important role in protecting the body against infectious diseases such as $\lg \mathrm{A}$, which are present at high concentrations in the early days of the infant's life, because they contain many antibodies that act as anti-viral, antibacterial against pathogens, which are 
particularly effective against the diseases which mother is exposed to, such as viral diseases, Streptococcus infection, and pneumonia, as well as its resistance to enzyme activity, and it is stable in the high acidic medium of stomach $(19,20$,).

\section{The role of dairy products in improving the immune system}

Dairy products such as fermented milk and skimmed yogurt made from unpasteurized milk, yogurt, and turkey cheese are rich in natural yeast. They play a vital role in fermenting undigested plant fibers and converting them into chemicals that seep into the bloodstream and help strengthen the immunity system (21), and help to lower cholesterol, which reduces the risk of heart disease, and to increase the useful microorganisms that reduce the allergist, malignant tumors, intestinal ulcers, diarrhea and reduce high blood pressure. It is necessary to increase the intake of skimmed yogurt because it increases the useful bacteria, especially in cases of illness or weakness or in cases of convalescence after surgery, so it is necessary to take one or two cups per meal $(22,23)$.

3. The role of vegetables and fruits in improving the immune system

It is preferable to eat fresh vegetables and salads at every meal, as well as fresh fruits to increase the efficiency of the immune system, especially for the patient of the digestive system and to clean the body (24).

4. The most important fruits that improves the immune system

Pomegranate, grapefruit, orange, strawberry, avocado, bananas, grapes, apples, pears, melons, berries, cantaloupe, cherries, kiwi, persimmons, pineapples, apricots, lemons, peaches, dates $(25,26,27)$.

5. The most important vegetable that improves the immune system

Cabbage, broccoli, broccoli, cauliflower, beetroot, carrots, pepper, radish, watercress, parsley, celery, red onion, garlic, pumpkin, eggplant, tomatoes, green beans, potatoes, spinach, artichoke, turnip $(28,29,30)$.

6. The role of drinking water in improving the immune system

Drinking two to three cups on the stomach early morning as well as drink extra amounts of water throughout the day by a glass of water 30 minutes before eating helps digestion, a glass of water before the bath helps to lower blood pressure, a glass of water before sleep prevents heart attack. Perhaps increasing water drinking works on the sedimentation of mucous membranes lining the respiratory tract, which helps the production of antibodies and white blood cells, thereby strengthening the immune system's performance $(31,32)$.

7. The most important cereals and legumes that improves the immune system

Soybeans, oats, flax, chickpeas, lentils, red beans, barley, fennel, sesame, non-peeled brown rice, corn, and wheat (33).

8. The most important transport materials for the immune system

Hazelnuts, nuts, almonds, peanuts, cashew nuts (33).

9. The most important germinated food that improves the immune system

Fenugreek and Al-Sham chickpeas (Homs Al-Sham) which eaten fresh and beans which eaten cooked (30).

10. The most important fruit juices and vegetable juices that improve the immune system

Beet juice, celery juice, fresh cabbage juice, asparagus juice, black grape juice, carrot juice, fresh apple juice, fresh lemon juice, orange juice, pineapple juice, pomegranate juice, cranberry juice, raspberry juice, apricot juice, peach juice, pear juice, strawberry juice, cucumber with lemon juice and grapefruit with lemon juice $(30,33)$.

11. The most important green food that improves the immune system

Juices extracted from the organic wheat plant and small organic barley leaf extract, organic oats grasses extract, spirulina, chlorella, organic green dandelion, green broccoli, organic spinach, organic kale, organic parsley, organic cauliflower, sea kelp, sea dulse, marine Green Algae, and Marine Vegetables $(34,35)$.

12. The most important functional foods that improve the immune system

Fiber, fish oils, mushroom, tempeh (fermented soybean product), turmeric, black tea, green tea, oligosaccharides, fermented dairy products, wheat germ, flaxseed oil, olive oil, corn oil, garlic, raspberries, ginger, lignin, lycopene, seafood rich in omega-3 (tuna and salmon) $(35,36)$. In addition to foods that improve the immune system, some vitamins share food in this content, including vitamins E, D, C, A, Folic acid, B12 and B6 which play a role in improving the immune system (37).

13. The most important mineral elements that improve the immune system

Metal elements such as iron, zinc, selenium, and copper play an important role in improving the immune system $(37,38)$.

14. The most important dietary supplements that improve the immune system

There are many dietary supplements that improve the immune system, including but not limited to:

Bee pollen 500-poll energy $520 \mathrm{mg}$-Roy Alton (Bee pollen +Wheat germ oil)-Tonic(Echinacea+Bee propilis $+\mid$ Nigella SativExt.+Cod Liver oil)-Echinacea purpurea $200 \mathrm{mg}+$ syrup - Echinacea drops - furan capsules (Echinacea purpurea $200 \mathrm{mg}$ +Echinacosides 4\%)-Lmmulant(Echinacea purpurea $175 \mathrm{mg}$ )Lmmulant capsulesplus(Echinacea purpurea $125 \mathrm{mg}+$ Goldenseal root $500 \mathrm{mg}$ )

Lmmulant syrup (Echinacea purpurea $1.6 \mathrm{mg}+$ Nigella Stiva oil $0.16 \mathrm{ml} / 100 \mathrm{ml}$.)-Lmmulant Sachet(Echinacea Purpurea + golden Seal root . - Lmmulone tablets(Echinacea purpurea + Vit.C)-Lmmuntvita Capsusles (Echinacea purpurea $210 \mathrm{mg}$ ).-lmmunvita drops (Echinacea purpurea $4.7 \mathrm{gm} / 25 \mathrm{ml}$ ) Mulone syrup (Chinacea purpurea)- 
Doranga sachet (Echinacea purpurea + Vit.C)-lmmuno Flu capsules (Echinacea purp + Vit.C + Zinc citrate) Lmmuno plus capsules (Echinacea purpurea $125 \mathrm{mg}$ + Nigella sativa seed powder $250 \mathrm{mg}$ ) - prostamune capsules (Echinacea purpurea + pumpkin seed oil + pumpkin Kamela + Vit.C)-Immu.C Sach (eff) (Echinacea purpurea 200 mg + Vit.C) - Immu.C Babe-Ton Sachet(Ext. of Thymus vulgaris + Fennel oil + Rose-Hips) - pc Sachet(Licorice $0.5 \mathrm{mg}+$ Majoum $0.5 \mathrm{mg}+$ Thyme $1 \mathrm{gm}+$ Lactose $1 \mathrm{gm}$ ) (39).

\section{The role of probiotics in improving the immune system}

There is a type of bacteria that live in the intestines, especially the colon, a bacteria that does not cause the disease but has a protective properties against diseases and its number is about 100 trillion bacterial cells, and this number is equivalent to ten times the cells of the body and because of these bacteria which have many benefits, including resistance to disease, they have been called friendly bacteria or probiotics bacteria and one of its benefits is resisting the microbes that invade the digestive system and cause a microbial infection leading to disorders in the digestive system, such as colitis and abdominal pain, as well as it causes fever. These friendly bacteria are a factory to produce many essential vitamins for the body, one of the probiotic bacteria that improve the cellular immunity in the elderly is Bifidobacterium lactis HN019, a friendly bacteria found in fermented dairy products that play an important role in improving gastrointestinal immunity against pathogenic microbes and preventing colon cancer. America and some European and Asian countries produced pharmaceutical prebiotic as an alternative to friendly microbes in the elderly $(33,40,41)$.

\section{The role of volatile oils and aromas in improving the immune system}

Volatile oils and aromas such as chamomile and lavender oils, coconut oil are used as an ointment to increase the immunity of the skin since they consider as protective substances that protect the body from infection (26).

\section{The role of healthy food in improving the immune system}

Perhaps the most important elements that maintain our immune system is a healthy balanced diet, which contains all the nutrients of proteins, carbohydrates, fats, vitamins and minerals in a balanced proportions with the adoption of healthy eating habits, such as the increasing of eating vegetables and fresh fruits of all kinds because they contain many useful nutrients, nuts for their content of proteins and magnesium, fish because they contain zinc which works to produce blood cells that fight infection, yogurt, fiber, mushrooms, garlic and olive oil, which contain antioxidants. It is necessary to avoid intake of hydrogenated oils, saturated fats and starches in large proportions, especially fries' potato, chips, fast foods, high fat meats, fat dairy products, desserts such as cacao, cake and oriental sweets as they are rich in saturated fat, and reducing consuming of sugars, drinking carbonated water and juices as they have been shown to slow the activity of white blood cells in attacking microbes and reduce the efficiency of the immune system for the elderly, and reducing the intake of refined foods (White sugar, white salt, and white flour) and using the whole flour instead of the white flour and instead of the alternative salt of potassium salts. It is necessary to refrain from smoking since it produces free radicals to crash the immune cells in the body, cigarette smoke contains thousands of chemical substances and the most influential one is nicotine as it affects the central nervous system, increasing adrenaline secretion and blood pressure, faster heartbeat and metabolic processes, and affects the immune system because cigarette smoke contains high concentrations of the nitrogen dioxide ozone compound, which oxidizes antioxidant vitamins and causes DNA breakdown, which in turn accelerates aging and weakens immunity. Eating balanced healthy food accompanied by a simple exercise, especially walking 20-30 minutes a day with exposure to indirect sunlight that works to form vitamin D, while listening to quiet, non-loud music for half an hour a day helps to enhance and improve immune system efficiency $(29,36,38,42$,

\section{References}

1- Janeway, C. A., Travers, P., Walport, M. \& Shlomchik, M. (1996), "Immunobiology: the immune system in health and disease", (Vol. 7, p. 26). London: Current Biology.

2- Balch, J.F. \& Balch, Ph. A. (1997), "Prescription for nutritional healing”, 2 nd Edition, Avery publishing Group, Garden city park ,New york .

3- Wahlqvist, M. L. (2002), "Food and nutrition", Australasia, Asia and the Pacific (No. Ed. 2). Allen \& Unwin.

4- Natesh, H. N., Abbey, L. \& Asiedu, S. K. (2017), “An overview of nutritional and antinutritional factors in green leafy vegetables", Horticult Int J, 1(2), 00011.

5- Allen, J., \& Hector, D. (2005), "Benefits of breastfeeding", New South Wales public health bulletin, 16(4), 4246.

6- Anderson, R. M. \& May, R. M. (1985), "Vaccination and herd immunity to infectious diseases", Nature, 318(6044), 323.

7- Gephart, S. M., Weller, M. \& Gephart, S. (2014), "Colostrum as oral immune therapy to promote neonatal health", Advances in Neonatal Care, 14(1), 44-51.

8- Cacho, N. T. \& Lawrence, R. M. (2017), "Innate immunity and breast milk", Frontiers in immunology, 8, 584.

9- Ballard, O. \& Morrow, A. L. (2013), "Human milk composition: nutrients and bioactive factors", Pediatric Clinics, 60(1), 49-74. 
10- Fichter, M., Klotz, M., Hirschberg, D. L., Waldura, B., Schofer, O., Ehnert, S. \& Schäfer, K. H. (2011), "Breast milk contains relevant neurotrophic factors and cytokines for enteric nervous system development", Molecular nutrition \& food research, 55(10), 1592-1596.

11- Magacz, M., Kędziora, K., Sapa, J. \& Krzyściak, W. (2019), “The Significance of Lactoperoxidase System in Oral Health: Application and Efficacy in Oral Hygiene Products”, International journal of molecular sciences, 20(6), 1443.

12- Irvine, D. J., Hanson, M. C., Rakhra, K. \& Tokatlian, T. (2015), “Synthetic nanoparticles for vaccines and immunotherapy", Chemical reviews, 115(19), 11109-11146.

13- Janeway, C. A., Travers, P., Walport, M. \& Shlomchik, M. (1996), "Immunobiology: the immune system in health and disease", (Vol. 7, p. 26). London: Current Biology.

14- Campos, L. F., Repka, J. C. D. \& Falcão, M. C. (2013), "Effects of human milk fortifier with iron on the bacteriostatic properties of breast milk", Journal de Pediatria (Versão em Português), 89(4), 394-399.

15- Siqueiros-Cendón, T., Arévalo-Gallegos, S., Iglesias-Figueroa, B. F., García-Montoya, I. A., Salazar-Martínez, J. \& Rascón-Cruz, Q. (2014), “Immunomodulatory effects of lactoferrin”, Acta Pharmacologica Sinica, 35(5), 557.

16- Schepers, A. W., Thibault, J. \& Lacroix, C. (2002), "Lactobacillus helveticus growth and lactic acid production during $\mathrm{pH}$-controlled batch cultures in whey permeate/yeast extract medium. Part I. Multiple factor kinetic analysis", Enzyme and microbial technology, 30(2), 176-186.

17- Reddy, G., Altaf, M. D., Naveena, B. J., Venkateshwar, M. \& Kumar, E. V. (2008), “Amylolytic bacterial lactic acid fermentation”, a review. Biotechnology advances, 26(1), 22-34.

18- Heine, R. G., AlRefaee, F., Bachina, P., De Leon, J. C., Geng, L., Gong, S. \& Rogacion, J. M. (2017), "Lactose intolerance and gastrointestinal cow's milk allergy in infants and children-common misconceptions revisited", World Allergy Organization Journal, 10(1), 41.

19- Hurley, W. L. \& Theil, P. K. (2011), "Perspectives on immunoglobulins in colostrum and milk", Nutrients, 3(4), 442-474.

20- Kaetzel, C. S. (2014), "Cooperativity among secretory IgA, the polymeric immunoglobulin receptor, and the gut microbiota promotes host-microbial mutualism”, Immunology letters, 162(2), 10-21.

21-Conlon, M. \& Bird, A. (2015), “The impact of diet and lifestyle on gut microbiota and human health", Nutrients, 7(1), 17-44.

22- Balch, P. A. (2006), "Prescription for nutritional healing. Penguin.

23- Hunter, B. T. (2008), "Probiotic foods for good health: Yogurt, sauerkraut, and other beneficial fermented foods", Basic Health Publications, Inc..

24- Dhandevi, P. E. M. \& Jeewon, R. (2015), "Fruit and vegetable intake: benefits and progress of nutrition education interventions-narrative", review article. Iranian journal of public health, 44(10), 1309.

25- Sinha, N., Sidhu, J., Barta, J., Wu, J. \& Cano, M. P. (Eds.). (2012), "Handbook of fruits and fruit processing”, John Wiley \& Sons.

26- Kushi, L. H., Doyle, C., McCullough, M., Rock, C. L., Demark-Wahnefried, W., Bandera, E. V. \& American Cancer Society 2010 Nutrition and Physical Activity Guidelines Advisory Committee. (2012), "American Cancer Society Guidelines on nutrition and physical activity for cancer prevention: reducing the risk of cancer with healthy food choices and physical activity", CA: a cancer journal for clinicians, 62(1), 30-67.

27- Calder, P. C. (2013), “Feeding the immune system”,Proceedings of the Nutrition Society, 72(3), 299-309.

28- Balch, P. A. (2003), "Prescription for dietary wellness", Penguin.

29- Donsbach, K.W. (1985), "Donsbach's Guide to Good Health - Long”, Shadow Books.

30- Steinmetz, K. A. \& Potter, J. D. (1996), "Vegetables, fruit, and cancer prevention", a review. Journal of the american dietetic association, 96(10), 1027-1039.

31- Popkin, B. M., D'Anci, K. E. \& Rosenberg, I. H. (2010), "Water, hydration, and health”, Nutrition reviews, 68(8), 439-458.

32- Petraccia, L., Liberati, G., Masciullo, S. G., Grassi, M. \& Fraioli, A. (2006), "Water, mineral waters and health", Clinical nutrition, 25(3), 377-385.

33- Jacobson, M. F., Lefferts, L. Y. \& Garland, A. W. (1991), "Safe food: Eating wisely in a risky”, world. Living Planet Press.

34-Wardlaw, G. M. \& Kessel, M. W., (2002), "Perspectives in Nutrition,” 5th Edition, McGraw-Hill Education, New York, 2002.

35- David, A., Gail, D. \& Adrianne, B. (2004), “Diet and human immune function”, New Jersy: Humane Press Inc.

36- Munkyong, P., Simin, M. \& Dayong, Wu (2012), “The Role of Nutrition in Enhancing Immunity in Aging”, Aging and Disease. 3 (1): 91-129.

37- Ronald, W. (2009), "Hand Book of Nutrition in the Aged", 4th Edition. Taylor and Francis Group - New York.

38- Hodkinson, C. F., Kelly, M., Alexander, H. D., Bradbury, I., Robson, P. J., Bonham, M. P. \& Wallace, J. M. 
(2007), "Effect of zinc supplementation on the immune status of healthy older individuals aged 55-70 years: the ZENITH Study", The Journals of Gerontology Series A: Biological Sciences and Medical Sciences, 62(6), 598-608.

39- Estafanous, A., Fathy, A. \& Anwar, J. (2010), "Physician Drug Index”, Handbook - 6th Edition - GNP Egypt.

40- Arunachalam, K., Gill, H. S. \& Chandra, R. K. (2000), "Enhancement of natural immune function by dietary consumption of Bifidobacterium lactis (HN019) ”, European Journal of Clinical Nutrition, 54(3), 263.

41- Gill, H. S., Rutherfurd, K. J., Prasad, J. \& Gopal, P. K. (2000), "Enhancement of natural and acquired immunity by Lactobacillus rhamnosus (HN001), Lactobacillus acidophilus (HN017) and Bifidobacterium lactis (HN019) ", British Journal of Nutrition, 83(2), 167-176.

42- Krause, D., Mastro, A. M., Handte, G., Smiciklas-Wright, H., Miles, M. P. \& Ahluwalia, N. (1999), "Immune function did not decline with aging in apparently healthy", well-nourished women. Mechanisms of ageing and development, 112(1), 43-57. 